\title{
Guamán Poma de Ayala como traductor indígena de textos culturales: La Nueva Corónica y Buen Gobierno (c. 1615)
}

\author{
Sabine Fritz \\ Justus-Liebig Universidad, Giessen, Alemania \\ sabinefritz@gmx.net
}

\begin{abstract}
Resumen
La conquista y la colonización del reino de los incas (1532) pueden ser caracterizadas como un gigantesco acto de traducción entre diferentes textos culturales y distintos métodos de transmisión. Los traductores tenían una función mediadora entre conquistadores y conquistados en la sociedad colonial y desempeñaban un papel importante y poderoso en el proceso de oscilación de códigos culturales y de negociación de identidades y alteridades. Un ejemplo de traducción de textos culturales es la Nueva Corónica y Buen Gobierno (c 1615), escrita por Felipe Guamán Poma de Ayala. Este artículo analiza los textos culturales que conoce el autor y la posición en la que se ve a sí mismo. Por un lado, se muestra cómo funciona el proceso de transmisión de textos culturales andinos, originariamente de manera oral, al medio de la escritura; por otro lado, se llama la atención sobre las estructuras del poder subyacentes en el proceso de la traducción.

Palabras clave: GUAMÁN POMA DE AYALA, PERÚ, SIGLO XVII, CRÓNICAS, HISTORIA CULTURAL.
\end{abstract}

\begin{abstract}
The conquest and colonization of the Inca Empire (1532) can be characterized as a giant translation process between different cultural texts and distinct methods of their transmission. Translators functioned in the colonial society as mediators between the conquerors and the conquered and played an important and powerful role in the oscillation of cultural codes and the negotiation between identities and alterities. One translation of cultural texts, in which the structures underlying the transition to colony and literacy from an indigenous perspective become evident, is the Nueva Corónica y Buen Gobierno (c 1615). Written by the Indian Felipe Guamán Poma de Ayala, it is addressed as a chronicle in form of a letter to the spanish king, Philip III. The article analyzes the cultural texts known by the author and the position in which he sees himself. On the one hand, we thus demonstrate, how the process of transmission of cultural andean texts, originally transmitted orally, into the written medium works. On the other hand, we call attention to the structures of power underlying the translation process.
\end{abstract}

Key words: GUAMÁN POMA DE AYALA, PERU, $16^{\mathrm{TH}}$ CENTURY, CHRONICLE, CULTURAL HISTORY. 


\begin{abstract}
Atagualpa Ynga fue degollad[o] y sentenciado y le mandó cortar la caueca don Francisco Pizarro. Y le notifica con una lengua yndio Felipe, natural de Guanca Bilca. Este dicho lengua le enformó mal a don Francisco Pizarro y los demás. No le gustó la dicha sentencia, y no le dio a entender la justicia que pedía y merced Atagualpa Ynga, por tener enamorado de la coya, muger lexítima. Y ací fue causa que le matasen y le cortasen la cauesa a Atagualpa Ynga y murió mártir cristianícimamente; en la ciudad de Caxamarca acabó su vida ${ }^{1}$.
\end{abstract}

Con la conquista y la colonización del reino de los incas chocaron dos culturas ajenas, lo que tuvo consecuencias profundas que son bien conocidas y perceptibles hasta hoy en día. Se ha negado durante mucho tiempo, incluso hasta el siglo pasado, que hubiese existido un diálogo entre las culturas europeas y andinas, sosteniendo una bipartición entre una cultura superior y una cultura inferior, así como una comunicación de dirección única que obligó a las voces de los conquistados a callar. No obstante, la convivencia de las culturas en el mismo espacio de hecho exigía ya desde el principio actos de comunicación que no eran unidireccionales, sino que activaban la oscilación de diversos códigos que transformaron las normas e imágenes del mundo tanto de los conquistados como de los conquistadores. Así, la perspectiva monolítica de la investigación académica ha sido finalmente relativizada con el cambio del discurso representativo de la conquista a partir del siglo XX y la era del poscolonialismo. En las últimas décadas del siglo XX, los documentos indígenas sobre la Conquista y la Colonia han sido reevaluados y la investigación académica ha puesto su atención en los procesos de inter y transculturación, así como de hibridación, en el sentido aludido por Bhabha $^{2}$. El diálogo en el contexto de la Conquista implicó, por cierto, la necesidad de una mediación no solo entre diferentes idiomas, sino también entre diferentes visiones del mundo y distintas formas de la codificación cultural, con una justificada caracterización como un gigantesco acto de traducción entre culturas distintas, así como un fuerte enlace entre traducción y poder.

\footnotetext{
${ }^{1}$ Guamán Felipe Poma de Ayala, Nueva Corónica y Buen Gobierno, eds. Rolena Adorno, John V. Murra y Jorge L. Urioste (Madrid: Historia 16, 1987), 393. Citado con la abreviación $N C$ de aquí en adelante.

${ }^{2}$ Homi Bhabha, The Location of Culture (Londres y Nueva York: Routledge, 1994).
} 


\section{Figura 1}

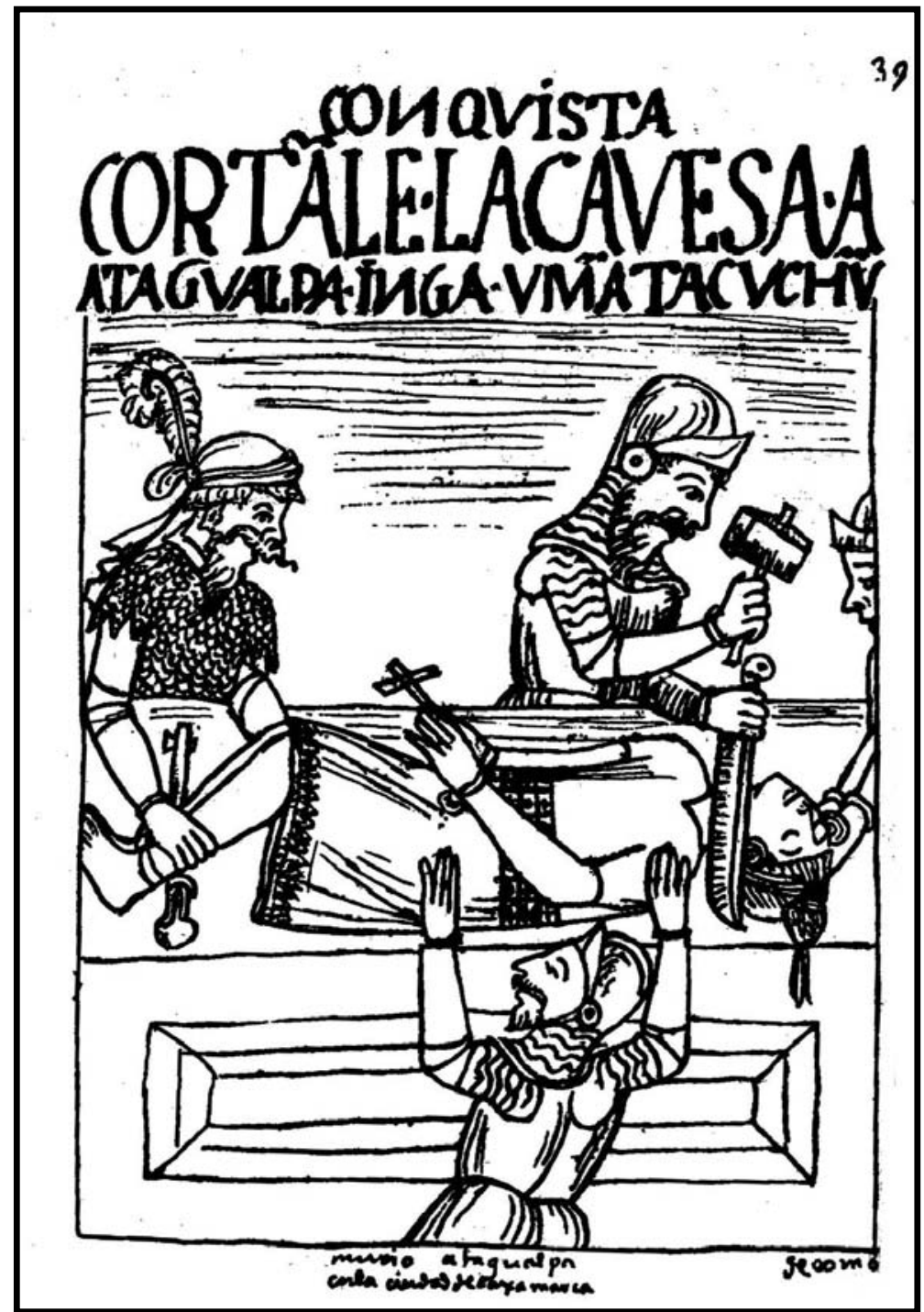

/390 [392]/ CONQUISTA / CÓRTANLE LA CAVESA A ATAGVALPA INGA / VMANTA CVCHVN [Le cortan la cabeza.] / Murió Atahualpa en la ciudad de Caxamarca.

Tomado de: Felipe Guamán Poma de Ayala, El primer Nueva Corónica y Buen Gobierno, eds. John V. Murra y Rolena Adorno, (México: Siglo XXI, 1980), 2: 362. 


\section{Traducciones y traductores en la sociedad colonial}

Las lenguas entre las que mediaron los traductores de los Andes eran, por un lado, el español y, en lo que concierne a la evangelización, en parte también el latín, mientras que, por otro lado, existía una gran cantidad de idiomas y dialectos andinos, a veces no comprensibles entre si ${ }^{3}$. En la sociedad colonial, ello condujo tanto a necesitar gran número de intérpretes como también a intentar establecer una base comunicativa común, es decir, una lengua general. El asunto sirvió incluso a los intereses de los conquistadores, especialmente en relación con la deseada evangelización, para la cual no les quedó otra alternativa que entenderse con la población indígena ${ }^{4}$. Solo con los esfuerzos de los misioneros españoles, la lengua runa simi, que desde entonces fue llamada quechua, llegó a tener gran divulgación en el área andina.

Una controversia entre los eclesiásticos españoles alude a la problemática de actos de traducción que dificultaban de manera decisiva la comunicación intercultural en la Colonia: unos opinaron que una evangelización profunda de los indígenas únicamente podía ser realizada usando sus lenguas andinas autóctonas. Sin embargo, este proceso se vio dificultado por la multitud de lenguas andinas todavía existentes. En contra de esta corriente, argumentaban otros que las lenguas indígenas implicaban tradiciones paganas $\mathrm{y}$, en consecuencia, imposibilitaban la traducción adecuada de términos católicos, justificando así que la evangelización tenía que ser ineludiblemente en español.

Por otro lado, en el contexto de la Conquista también se dio el enfrentamiento de diferentes textos culturales y métodos de transmisión. Con Bachmann-Medick entendemos aquí el concepto de texto en su sentido amplio, que implica no solo textos escritos, sino todas las simbolizaciones y señas en las que se manifiesten informaciones culturales específicas, es decir, tanto literatura o textos administrativos como arte, pintura, fiestas y ritos, teatro, etc. ${ }^{5}$ Por consiguiente, los textos culturales pueden ser considerados como manifestaciones de la "memoria cultural" en la que se media y se estabiliza una identidad colectiva, o sea, un saber común del pasado y del mundo que, para un grupo dado, representan la base de su

\footnotetext{
${ }^{3}$ Alfredo Torero, Idiomas de los Andes. Lingüistica e historia (Lima: IFEA, 2002).

${ }^{4}$ Michael Sievernich, "'Christianorum avaritia indorum vocatio'. Eine theologische Sicht der 'Neuen Welt' im späten 16. Jahrhundert', Der eroberte Kontinent. Historische Realität, Rechtfertigung und literarische Darstellung der Kolonisation Amerikas, ed. Karl Kohut (Frankfurt a. M.: Vervuert, 1991), 111. Iris Gareis, Die Geschichte der Anderen. Zur Ethnohistorie am Beispiel Perus (Berlín: Reimer, 2003), 205.

5 Doris Bachmann-Medick, Kultur als Text. Die anthropologische Wende in der Literaturwissenschaft (Frankfurt a. M.: Fischer, 1996).
} 
conciencia tanto de unidad como de particularidad ${ }^{6}$. En este sentido, funciona como un proceso de diferenciación y afiliación, como negociación de identidades y alteridades.

Las visiones del mundo que chocaron en el contexto de la Conquista estaban fundadas en estructuras simbólicas diferentes, ya fuera que procedieran de una cultura oral o de una letrada. Una premisa importante de las culturas orales es la necesidad de un contexto específico de presentación. Digamos que se trata de una memoria corporal y performativa. Narrador y público entran en una relación intensiva e interactiva, en la que el público, por sus reacciones, puede participar de manera creadora en la narración. Aquí juega un papel importante el contexto, es decir, el lugar, el tiempo y la identidad de los interlocutores -ya que, como subraya Mannheim, "no solo se quiere dar a conocer la historia, sino, también, los mundos culturales tanto del narrador como del oyente" generalmente con la repetición basada en la primacía de la mnemotécnica. La escritura, entonces, posibilita la desvinculación del saber de los individuos y da independencia y autonomía al texto escrito, que, una vez independizado del redactor del texto, puede ser duplicado ilimitadamente por la imprenta; los receptores, en su mayor parte desconocidos por el autor, quedan sin conexión directa con él y no pueden, por tanto, plantear preguntas. Al mismo tiempo, las formas mnemotécnicas pierden su importancia existencial; en vez de la repetición, es la variación lo que se considera como característica de un "buen" texto escrito".

Por consiguiente, las codificaciones culturales andinas o españolas se vieron separadas no solo por una frontera lingüística, sino también por maneras de narración y transmisión muy distintas, y dieron paso al malentendido cultural, dificultando todavía más la tarea de la traducción. Notorias son, por ejemplo, las frecuentes quejas de los cronistas españoles acerca de las narraciones supuestamente incompletas y anacrónicas de los indígenas, que entendían en general como señal de su inferioridad intelectual. Una traducción meramente literal no habría sido capaz de revalorar el mundo andino para un público europeo.

Nos preguntamos, entonces, dónde se podrá consultar hoy en día una traducción de textos culturales en la que se manifiesten las estructuras subyacentes a la cultura letrada de la Colonia, desde una perspectiva indígena. El hecho de que los documentos redactados por indígenas en este tiempo y conocidos por la investigación académica de hoy sean escasos los hace aún más valiosos para el

\footnotetext{
6 Jan Assmann, "Kollektives Gedächtnis und kulturelle Identität", en Kultur und Gedächtnis, ed. Toni Hölscher (Frankfurt a. M.: Suhrkamp, 1988).

${ }^{7}$ Bruce Mannheim, "Hacia una mitografía Andina", en Tradición oral andina y amazónica. Métodos de análisis e interpretación de textos, ed. Juan Carlos Goddenzi Alegre (Cuzco: CBC, 1999), 48.

${ }^{8}$ Jan Assmann, Das kulturelle Gedächtnis (München: Beck 1992).
} 
análisis de la negociación de la identidad indígena en la sociedad colonial. Las crónicas sobre el pasado andino y el presente colonial escritas por indígenas presentan, por su exigencia de representación integral, informaciones particularmente amplias sobre los contenidos de la memoria cultural. Digamos que son textos culturales por excelencia.

El hecho de que la mayoría de los textos indígenas fueran escritos en español y dirigidos a receptores españoles, es decir, a otra cultura, demuestra que los actos de traducción componen un factor esencial en este contexto -actos que, por cierto, fueron influenciados particularmente por el traductor-autor y por su relación con el lector implícito-. Esto se evidencia, según Gareis ${ }^{9}$, especialmente en las crónicas del Perú, que se dirigen a un público español, tal y como sucede en el caso del texto que analizaremos aquí, la bien conocida Nueva Corónica y Buen Gobierno $(N C)$, de la que justificadamente dice Cummins:

El descubrimiento de más de mil páginas de dibujos y textos dirigidos al rey Felipe II es una mina tan rica para los académicos del siglo veinte, como lo fue el descubrimiento de Potosí para los españoles del siglo dieciséis ${ }^{10}$.

Esta crónica fue redactada por el indígena Guamán Poma de Ayala principalmente en español, con algunas inserciones en lenguas andinas. Está dirigida como una carta de 1.189 páginas al rey español Felipe III. En la primera parte, denominada Nueva Corónica, se describe la historia precolombina de los Andes hasta el reino de los incas y la conquista. En la segunda parte, titulada Buen Gobierno, el autor pasa a la descripción de la realidad colonial y toma el papel de consejero del rey, pidiendo para la población indígena la mejora de sus condiciones de vida. El autor incorpora en su carta crónica 398 dibujos hechos por él mismo y sugiere que estos dibujos deberían facilitar el proceso de lectura al rey:

... escrito y debojado de mi mano y engenio para que la uaridad de ellas y de las pinturas y la enbinción y dibuxo a que vuestra Magestad es enclinado haga fázil aquel peso y molestia de una lectura falta de enbinción y de aquel ornamento y polido ystilo que en los grandes engeniosos se hallan ${ }^{11}$.

\footnotetext{
${ }^{9}$ Gareis, Die Geschichte.

10 "The discovery of the more than one thousand pages of drawings and writings addressed to King Philip III is as rich a mine to twentieth-century scholars as the discovery of Potosí was to sixteenth-century Spaniards". Thomas Cummins, "Let me see! Reading Is For Them: Colonial Andean Images and Objects, 'como es costumbre tener los caciques Señores", en Native Traditions in the Postconquest World, eds. Elizabeth Hill Boone y Thomas Cummins (Washington, D.C.: Dumbarton Oaks, 1998), 91.

${ }^{11} N C, 10$.
} 
En lo que concierne a Guamán Poma y su traducción de textos culturales andinos para un receptor europeo, es de especial interés analizar los textos culturales que conoce, es decir, las estructuras simbólicas con las cuales está familiarizado por su socialización, educación y profesión, así como las formas discursivas en las que es competente y los idiomas que habla o entiende. Además, interesa la posición en la que se ve a sí mismo como traductor indígena, para ver cómo funciona la negociación de identidad y alteridad desde la perspectiva de un autor indígena.

\title{
El traductor indígena
}

\begin{abstract}
¿Quién podrá escriuille ni hablalle ni allegarse a un personage tan gran señor cristiano católico, Sacra Católica Real Magestad? Y ací se atreuió su bazallo de su corona rreal y su cauallero deste rreyno de las Yndias del Mundo Nuebo que es príncipe, quiere decir auqui, de este rreyno, nieto del rrey décimo, Topa Ynga Yupanqui, hijo lexítimo de doña Juana Curi Ocllo, coya, quiere dezir coya, rreyna del Pirú. Y ací ubo de escriuilla y trauajarlo la dicha Nueva corónica y buen gobierno $^{12}$.
\end{abstract}

La información biográfica que tenemos sobre Guamán Poma, el "bazallo de su corona rreal", proviene principalmente de sus propias revelaciones en la $N C$. Estas no siempre tienen que corresponder con la "realidad histórica", pero siempre son reveladoras de la posición en la que el autor se ve o se tiene que ver. Nació como hijo de padres andinos, probablemente algunos años después de la conquista del reino de los incas. Su familia pertenecía a un pueblo conquistado por los incas, a los que evidentemente sirvió con lealtad, ya que Guamán Poma habla de su padre repetidas veces como "segunda persona del mismo Ynga"13. El futuro autor de la crónica habría tenido en sus primeros años una socialización de carácter andino, ya que en la $N C$ demuestra conocimientos íntimos de la sociedad andina.

Como muchos indígenas de su tiempo, al pertenecer a la élite andina provincial, Guamán Poma intentó asegurarse una posición privilegiada en la sociedad colonial, que implicaba ineludiblemente la prueba de haber sido convertido al cristianismo. Según Guamán Poma, su hermanastro mestizo Martín de Ayala participó de manera decisiva en su educación cristiana. El padre "le puso [a Martín] en estudio y dotrina" ${ }^{\prime 4}$, supuestamente a los doce años. Esto puede indicar que haya

\footnotetext{
${ }^{12} N C, 1137-1138$.

${ }^{13} N C, 16$.

${ }^{14} \mathrm{NC}, 15$.
} 
frecuentado una de las escuelas fundadas por los españoles para difundir activamente la lengua y la religión de los conquistadores. Los conocimientos obtenidos allí los transmitió evidentemente a sus hermanos: "Y el dicho sancto hombre le enseñó a sus hermanos y al autor deste dicho libro, por dónde se bino a escriuirse la dicha Primer corónica"15. A través de la descripción idealizada de este personaje y de su vida, caracterizada por analogías con la vida de Jesús, Guamán Poma pone énfasis en la profundidad de su educación cristiana, que lo familiarizó, ya en sus años tempranos, con un texto cultural paradigmático del mundo cristiano: la Biblia.

En este período, como también en tiempos sucesivos, debe haber experimentado los métodos de enseñanza de la Iglesia católica. A estos pertenecen formas principalmente de carácter oral -la oración, el sermón, la disputación, el confesionario y el canto- tanto como la enseñanza escrita, sobre todo de la Biblia. Esta enseñanza fue evidentemente acompañada por el uso intensivo de imágenes, con lo que, por un lado, se presentaba la posibilidad de contrarrestar el analfabetismo y, por otro, se mostraba la influencia de la Contrarreforma en Europa, que

... entendió que la revitalización de la sensibilidad católica solo sería posible mediante el bombardeo simultáneo de los sentidos del cristiano con un mismo mensaje redundante. (...) Como foco importante de la Contrarreforma europea, España habría de llevar la política de comunicación visual tridentina a Indias, convirtiéndola en poderoso instrumento de catequización ${ }^{16}$.

El uso que Guamán Poma hace del medio visual puede haber sido motivado tanto por sus experiencias europeas como por las andinas, ya que la mnemotécnica andina también se sirvió de dibujos y pinturas ${ }^{17}$. Sin embargo, si tomamos en consideración a Cummins, el arte peruano siguió otras pautas distintas de las del arte europeo naturalista:

El arte encontrado por los españoles en el Perú era, en su mayor parte, abstracto, (...) no ilustraba figurativamente ideas (...). Representar el Perú ante los europeos significaba evitar formas y conceptos representacionales de los peruanos mismos, y

\footnotetext{
${ }^{15}$ Ibídem.

${ }^{16}$ Mercedes López-Baralt, Ícono y conquista. Guamán Poma de Ayala (Madrid: Hiperión, 1988), 124-125. "tridentina" se refiere al Concilio de Trento (1545-63), "que definió la posición de la Iglesia católica ante la revuelta protestante, decretó la legitimidad y conveniencia del uso de imágenes para la propagación de la fe". Ibídem.

${ }^{17}$ Véanse, por ejemplo, Juan Gargurevich Regal, La comunicación imposible. Información y comunicación en el Perú, siglo XVI (Lima: Umnsm, 2002); Juan José Pacheco Ibarra, "La pintura de los incas. Un arte olvidado", Uku Pacha (Lima),1 (2000): 36-55, y Fernando Prada Ramírez, Der Tanz um den Buchstaben. Die semantischen Systeme des 16 Jahrhunderts in den Anden (Regensburg: Roderer, 1994).
} 
cuando se deseaban imágenes pictóricas del Perú, se empleaban modos de representación europeos, basados en la mimesis ${ }^{18}$.

Aunque también se hallaron formas de arte naturalista en el mundo andino, existe, a causa de su menor uso y distribución, la posibilidad de que no hayan ejercido una gran influencia en Guamán Poma. Parece más bien que fue el simbolismo abstracto, a la vez incomprensible para el público europeo, lo que dejó sus huellas en la $N C$. En lo referente a la iconografía de Guamán Poma, nos informa Adorno que usa, por un lado, "el código artístico europeo de la iconografía cristiana religiosa" y, por otro, "el sistema andino de simbolismo espacial que organiza la composición de los dibujos"19. El sistema andino espacial se ve conectado íntimamente con un sistema de valores: es cuatripartito, con un centro, cada parte adquiere valores diferentes según su posición en el espacio entero ${ }^{20}$. Analizando las ilustraciones hechas por Guamán Poma con este sistema, Adorno ${ }^{21}-\mathrm{y}$ recientemente González et al. $^{22}$-, en un detallado análisis de cada una de las ilustraciones, han podido demostrar convincentemente que la mayor parte de ellos proponen valoraciones de lo ilustrado dando informaciones sobre la perspectiva de su dibujante. Es evidente, asimismo, que los dibujos también exigen un proceso de traducción. Dice Cummins al respecto que "el arte andino requería ser explicado o, mejor aún, traducido a una forma textual más que ser reproducido como ilustraciones" ${ }^{23}$. Guamán Poma, no obstante, usa la traducción gráfica en gran parte de su obra y la combina con la traducción textual de una manera única, creando, según Adorno ${ }^{24}$, una propia sintaxis visual que media entre las estructuras simbólicas andinas y las europeas.

Gracias a su educación, le fue posible a Guamán Poma trabajar como escritor e intérprete para la administración y jurisprudencia española. Por este trabajo, vino a conocer nuevas codificaciones culturales, catálogos de preguntas formuladas para las visitas o los confesionarios, expedientes y protocolos judiciales y otras formas de documentación administrativa, como inventarios o calendarios. Además, tuvo

\footnotetext{
${ }^{18}$ Thomas Cummins, "La representación en el siglo XVI: La imagen colonial del inca", en Mito y simbolismo en los Andes. La figura y la palabra, ed. Henrique Urbano (Cusco: CBC, 1993), 92-95.

${ }^{19}$ Rolena Adorno, introducción a Nueva Corónica y Buen Gobierno, por Guamán Felipe Poma de Ayala (Madrid: Historia 16, 1987): xxxv-xxxvi.

${ }^{20}$ Para un análisis revelador y detallado del sistema espacial andino y su aplicación en la $N C$, véase Rolena Adorno, "Paradigmas perdidos. Guamán Poma examina la sociedad española colonial”, Chungará (Chile), 13 (1984): 67-91.

${ }^{21}$ Ibídem.

${ }^{22}$ Carlos González, Hugo Rosati y Francisco Sánchez, Guaman Poma. Testigo del mundo andino (Santiago de Chile: LOM, 2002).

${ }^{23}$ Cummins, La representación en el siglo XVI, 92.

${ }^{24}$ Rolena Adorno, "Visual Mediation in the Transition from Oral to Written Expression," New Scholar (Santa Bárbara, Estados Unidos), 10.1 (1986): 181-97.
} 
acceso al discurso oficial de los colonizadores, el cual se caracterizó en este tiempo por fuertes controversias, entre otras, sobre la legitimidad de la conquista y sobre los métodos adecuados para la evangelización. Como varias de las estrategias argumentativas usadas en este contexto correspondían a la perspectiva personal de Guamán Poma, él las retoma más tarde en su obra ${ }^{25}$. El ejemplo más prominente es el tratado de Bartolomé de Las Casas, en el que denuncia la ilegitimidad de la conquista y exige la devolución de los territorios conquistados a sus legítimos propietarios indígenas, opinión que sostiene también Guamán Poma: "Y los yndios son propietarios naturales de este rreyno, y los españoles, naturales de España. Acá en este rreyno son estrangeros, mitimays. Cada uno en su rreyno son propetarios lexítimos, poseedores, no por el rrey cino por Dios y por justicia de Dios (...). El Ynga era propetario y lexítimo rrey,"26.

La competencia lingüística demostrada en la $N C$ revela que la lengua materna del autor evidentemente era un dialecto del runa simi. Debe haber aprendido el español posteriormente, ya que su obra está caracterizada por errores de transferencia y por hipercorrecciones que típicamente acompañan el aprendizaje de una lengua extranjera. Según sus propias indicaciones, conocía también otros dialectos andinos e incluso otros idiomas indígenas: "Escogí la lengua e fracis castellana, aymara, colla, puquina, conde, yunga, quichiua ynga, uanca, chinchaysuyo, yauyo, condesuyo, collasuyo, cañari, caqyanpi, quito",27. Es diciente que señale haber ido "ajuntando (...) todos los bocablos de yndios" ${ }^{28}$ en español, así como en los idiomas andinos. Debía haber tenido un listado de voces que habrá ampliado continuamente en el curso de sus viajes, lo que puede evidenciar que algunos de sus conocimientos de las lenguas mencionadas probablemente se limitaron a un entendimiento pasivo de algunas palabras.

Las observaciones hechas hasta aquí muestran que la $N C$ está basada en múltiples actos de traducción y, con esto, de interpretación: el autor tradujo el material que le narraron sus informantes en diferentes idiomas andinos, primeramente en su lengua natal, lo que implicó ya una interpretación correspondiente a su concepto del mundo. A medida que se familiarizó con otros conceptos culturales, nuevas formas de codificación entraron en su conocimiento personal del mundo y pudieron influenciar sus interpretaciones futuras. El siguiente acto de traducción ocurrió en la redacción de la $N C$ para su real destinatario español. En este nivel, se puede asumir una recodificación del material colectado, adaptándolo a codificaciones

\footnotetext{
${ }^{25}$ Para las fuentes de Guaman Poma, véase Rolena Adorno, "Felipe Guaman Poma de Ayala. An Andean view of the Peruian Viceroyaliy, 1565-1615", Journal de la Societé des Américanistes (París), 65 (1978): 121-143.

${ }^{26} N C, 929$.

${ }^{27} N C, 10$.

${ }^{28} N C, 11$.
} 
culturales y formas discursivas que, según la opinión del autor andino, debían ser comprensibles para el público español de ese tiempo.

Aproximadamente un quinto de la $N C$ está, además, compuesto por textos en quechua, que, según Urioste, "juntamente con los del manuscrito del Waru Chiri, son los únicos que nos presentan la visión del hombre andino desde un punto de

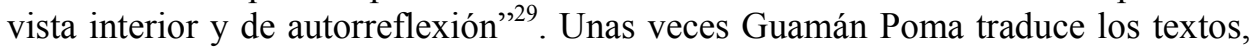
otras veces quedan sin traducir. Hay, por ejemplo, términos particulares, oraciones, canciones o diálogos fingidos en los que el autor imita los dialectos de los hablantes. Incluso la creolización de la lengua se ve imitada en algunas partes: "obeja chincando, pacat tuta buscando, manca tarinchos, uira cocha [una oveja se perdió y se ocultó. Dicen que no la encuentran al buscarla de noche] ${ }^{30}$. En aquellos casos en los que Guamán Poma sí presenta traducciones, según Urioste, estas son "generalmente interpretativas, una paráfrasis del texto quechua",31, como en el ejemplo siguiente:

Texto quechua de Guamán Poma: “'Tizce caylla uira cocha, maypim canqui? ¿Hanac pachapicho? ¿Cay pachapicho? ¿Uco pachapicho? ¿Caylla pachapicho? ¿Cay pacha camac, runa rurac, maypim canqui? ¡Oyariuay!’32.

Traducción literal ofrecida por Urioste: "Señor del fundamento y del más allá -o fundamental y cercano-, ¿dónde estás? ¿En el lugar superior? ¿En este mundo? ¿En el mundo inferior? ¿En la tierra del extremo -o cercana? Ordenador de este mundo, hacedor del hombre, ¿dónde estás? ¡Óyeme!”33.

Traducción ofrecida por el mismo Guamán Poma: "O, señor, ¿adónde estás? ¿En el cielo o en el mundo o en el cabo del mundo o en el ynfierno? ¿Adónde estás? ¡Oyme, hazerdor del mundo y de los hombres! ¡Oyme, Dios!”34.

Estamos completamente de acuerdo con Urioste en que Guamán Poma reinterpreta la cosmovisión andina con la aplicación de términos cristianos a conceptos precoloniales $^{35}$. Aquí traduce la clasificación tripartita andina del mundo hanan pacha, cay pacha y uco pacha por la división cristiana en cielo, mundo e "ynfierno". Este ejemplo parece ser una prueba del proceso interpretativo que subyace a toda la obra, dado que la $N C$ empieza con el Génesis, intenta integrar el

\footnotetext{
${ }^{29}$ Jorge L. Urioste, introducción a Nueva Corónica y Buen Gobierno, por Guamán Felipe Poma de Ayala (Madrid: Historia 16, 1987), lxv.

${ }^{30} N C, 397$, lxxi. subrayado SF.

${ }^{31}$ Ibídem.

${ }^{32} N C, 54$.

${ }^{33}$ Poma de Ayala, Nueva Corónica, lxix.

${ }^{34} \mathrm{NC}, 54$.

${ }^{35}$ Ibídem, lxix.
} 
pasado andino en la historia cristiana e introduce elementos iconográficos cristianos en las ilustraciones del mundo andino.

La selección del material y el traslado de las fuentes orales al medio escrito componen la base de estos procesos de codificación y recodificación y le conceden a Guamán Poma el poder de utilizar su competencia lingüística e intercultural para favorecer sus propias intenciones. Así, los párrafos en quechua representan la notación gráfica de una lengua originalmente usada solamente en la comunicación oral. No obstante esto, la fijación escrita no puede corresponder a la multitud de las versiones orales en circulación, lo que hace necesario una selección por parte del autor: "E trauaxado de auer para este efecto las más uerdaderas rrelaciones que me fueron pocibles, tomando la sustancia de aquellas personas; aunque de uarias partes me fueron traýdas, al fin se rredugían todas a la más común opinión" ${ }^{\text {"36. }}$.

"Las más uerdaderas", "sustancial” y "la más común opinión”, por cierto, son nociones muy subjetivas. Evidentemente, Guamán Poma usa el carácter modular y la forma situacional de la narrativa oral en el medio escrito para una elaboración de las informaciones seleccionadas correspondiente a su intención y situación personal.

\footnotetext{
${ }^{36} N C, 10$. Resaltados de la autora.
} 
Figura 2

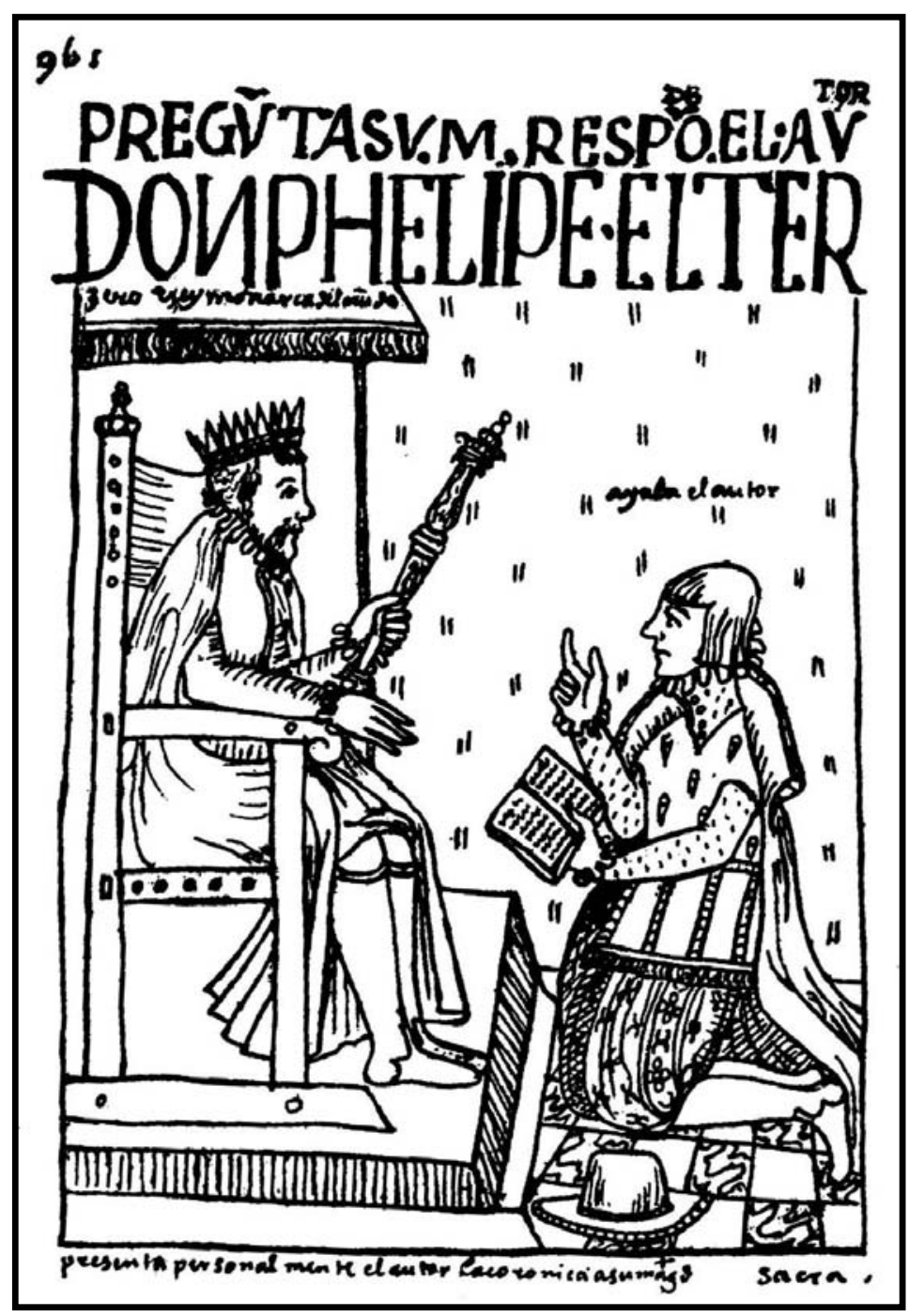

/961 [974]/ PREGUNTA SV MAJESTAD, RESPONDE EL AVTOR / DON PHELIPE EL TERZERO, rrey monarca del mundo / Ayala el autor / Presenta personalmente el autor la Corónica a su Magestad.

Tomado de: Felipe Guamán Poma de Ayala, El primer Nueva Corónica y Buen Gobierno, eds. John V. Murra y Rolena Adorno, (México: Siglo XXI, 1980), 3: 896. 


\title{
Traducción y poder
}

\author{
[Sacra Católica] Real Magestad: Mande vuestra \\ Magestad a su buen gobierno y audiencia rreal que \\ trate y onrre como a príncipes y señores y principales \\ deste nuestro [rey]no pues que emos leuantado y \\ seruido muy grandemente. (...) Vuestra Magestad \\ deste Nuebo Mundo con nuestros bazallos y [m]ás \\ con el serro de Potocí y otras minas (...). Y ancí \\ conbiene que nos honrre vuestra Magestad y \\ bendición de su Santidad ${ }^{37}$.
}

Quizás la más explícita explicación de su posición en la sociedad colonial la provee Guamán Poma en una conversación fingida con el rey español, la cual está titulada como "Capítulo de la pregunta"38. Guamán Poma escribe aquí un diálogo que, según su opinión, habría tenido lugar si le hubiera sido posible hablar personalmente con Felipe III. En la comunicación fingida, rey y autor aparecen hablando de forma directa el uno con el otro, así que se representa un intercambio entre los representantes de la cultura europea y la andina, respectivamente.

Un dibujo inicial ilustra esta situación: Está titulado "Pregunta Sv Magestad, responde el autor / don Phelipe el terzero, rrey monarca del mundo"39. Sobre la cabeza del autor aparece la inscripción "Ayala el autor" y debajo del dibujo se lee: "Presenta personalmente el autor la Corónica a su Magestad". Vemos al autor de rodillas ante el trono del rey, con la crónica abierta en su mano izquierda. Reverentemente, se ha quitado el sombrero y habla al rey con el índice de su mano derecha erguido. La vestimenta del autor indica su elevado estatus social en la sociedad colonial: su peinado y posiblemente el adorno de la vestimenta provienen de codificaciones culturales andinas, mientras el sombrero, la camisa, la capa y las botas corresponden a la moda de entonces de los caballeros españoles. Felipe III, caracterizado por una corona y un cetro, mira hacia el autor desde su trono. Los dedos de su mano derecha están un poco levantados y dan la impresión de conceder la palabra al autor.

\footnotetext{
${ }^{37} N C, 977$.

${ }^{38} \mathrm{NC}, 974$

${ }^{39} \mathrm{NC}, 975$.
} 
Figura 3

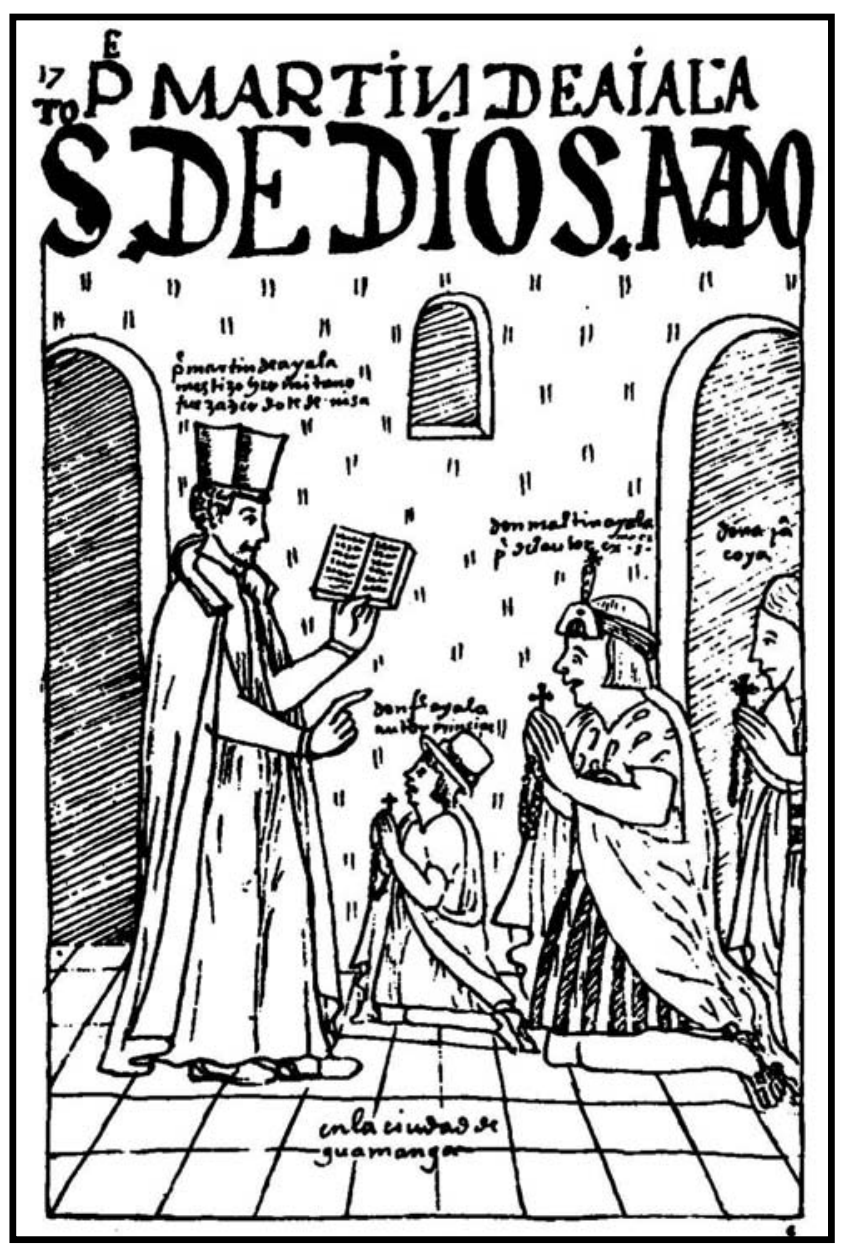

/17 [17]/ PADRE MARTÍN DE AIALA / SANTO DE DIOS AMADO / padre Martín de Ayala, mestizo ermitaño, fue zazerdote de misa / don Felipe Ayala, autor, príncipe / don Martín Ayala, padre del autor, excelentísimo señor / doña Juana, coya [reina] / en la ciudad de Guamanga.

Tomado de: Felipe Guamán Poma de Ayala, El primer Nueva Corónica y Buen Gobierno, eds. John V. Murra y Rolena Adorno, (México: Siglo XXI, 1980), 1:13. 
El gesto del índice levantado proviene probablemente de la iconografía europea y puede ser interpretado como señal de un acto comunicativo con contenidos importantes. Se lo puede observar sobre todo en las pinturas religiosas de la Edad Media referentes a las áreas de la escolástica y de la disputa religiosa ${ }^{40}$. En la disputa teológica, el gesto se ve en relación con la Biblia: el índice derecho está levantado, mientras que la mano izquierda reposa sobre la Biblia. Esto fue considerado como un signo de la autoridad de la Sagrada Escritura, por lo que, al mismo tiempo, se puso énfasis en la legitimidad y la veracidad de lo dicho. Guamán Poma habría aprendido esto durante su educación cristiana: existe un dibujo en la $N C$ que muestra a su hermanastro mestizo enseñándole a él y a sus padres, con la Biblia en la mano izquierda y el índice erguido ${ }^{41}$.

Lo mismo se puede observar en otras ilustraciones de la $N C$. Por ejemplo, en los dibujos "Consejo Real destos Reinos Capac Inga Tavantin Svio Camachicoc Apocona [los Inkas señores que gobiernan el Tawantin Suyu]"42 y "Pregvnta el Avtor / 'Ma, Villavai ['Pero, díganme'] Achamitama' [Aymara: 'Tu llanto desde allí']" "33. En ambas ilustraciones se evidencia una comunicación característica de culturas orales. El coleccionista de informaciones está en el centro con el índice levantado, rodeado por sus fuentes indígenas y un público anónimo, esbozado por un gran número de cabezas sin rostro en el fondo. Los índices levantados y los otros gestos de los informantes en el primer plano indican que se trata de una conversación animada y de contenidos importantes. Es llamativo que la figura de Guamán Poma, como coleccionista de material para la $N C$, corresponde en aspecto, vestuario y edad exactamente a la figura del autor en la conversación fingida con el rey, aunque, entre tanto, debían haber pasado muchos años. De esta manera, existe gráficamente una referencia a las informaciones recogidas de las fuentes orales y transmitidas al rey en la conversación fingida. Nótese que también la transferencia de las fuentes orales al medio escrito queda demostrada en las ilustraciones: mientras que la comunicación con los indígenas funciona sin noticias escritas algunas, en la conversación entre autor y rey la crónica es presentada como intermediaria entre los dos representantes de la cultura andina o española, respectivamente. Esta transmisión indica, asimismo, una revaloración de fuentes orales, presentándolas como fuentes fiables.

\footnotetext{
${ }^{40}$ Para las pinturas europeas del tiempo, véase el banco de datos "Realonline" del "Institut für mittelalterliche Realienkunde und der frühen Neuzeit" de la "Österreichische Akademie der Wissenschaft". Viena. Obtenido de la red mundial el 13 de septiembre de 2005. 10:00 horas. http://www.imareal.oeaw.ac.at/realonline. También el Códice Florentino opera con índices levantados; véase Bernardo de Sahagún, Historia general de las cosas de Nueva España, ed. Juan Carlos Temprano (Madrid: Historia 16, 1990).

${ }^{41} N C, 17$.

${ }^{42} N C, 366$.

${ }^{43} N C, 368$.
} 
Figura 4

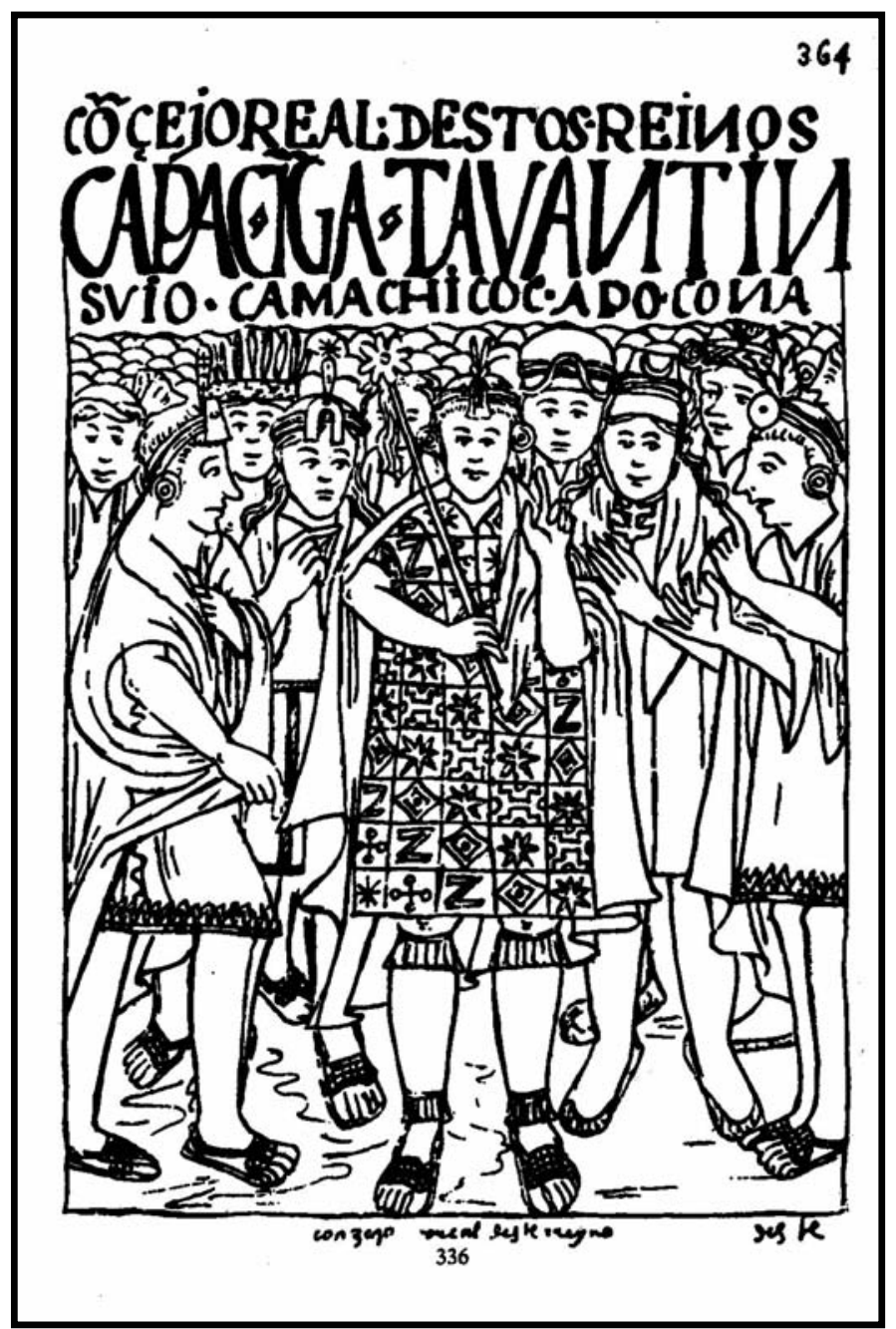

/364 [366]/ CONCEJO REAL DESTOS REINOS CAPAC INGA TAVANTIN SVIO CAMACHICOC $A P C O N A$ [Los inkas señores que gobiernan el Tawantin Suyu] / conzejo rreal deste rreyno.

Tomado de: Felipe Guamán Poma de Ayala, El primer Nueva Corónica y Buen Gobierno, eds. John V. Murra y Rolena Adorno, (México: Siglo XXI, 1980), 1:336. 
Figura 5

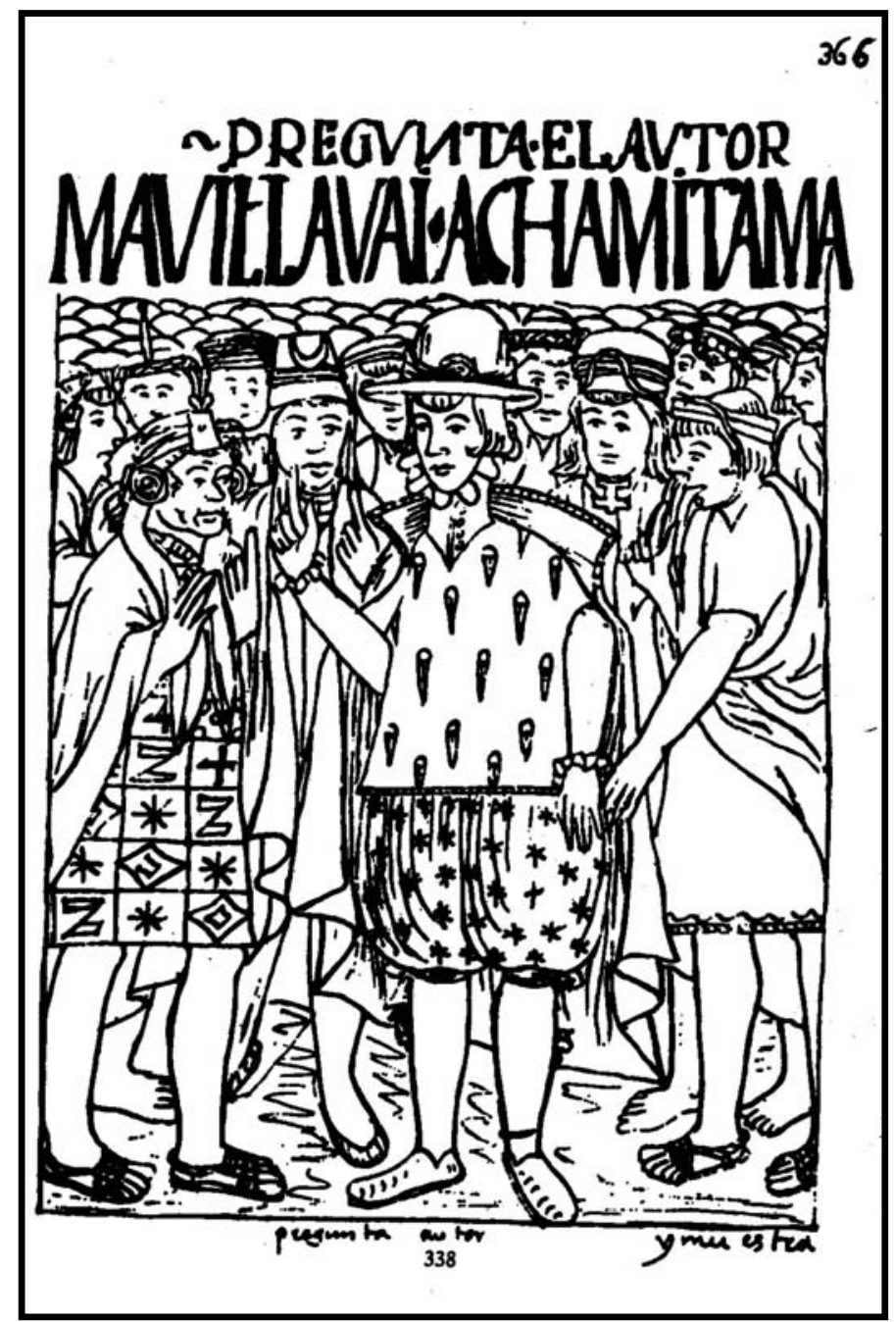

/366 [368]/ PREGVNTA EL AVTOR / "MA, VILLAVAI ["Pero, díganme"] ACHAMITAMA [Aymara: "Tu llanto desde alli'”] / Pregunta autor.

Tomado de: Felipe Guamán Poma de Ayala, El primer Nueva Corónica y Buen Gobierno, eds. John V. Murra y Rolena Adorno, (México: Siglo XXI, 1980), 1:338. 
Si Guamán Poma, en el contexto de la conversación fingida con el rey español, usa el gesto del índice levantado en relación con la $N C$, no solo deja en evidencia el gran valor que le otorga a su crónica, sino también usa una indicación que hace esta valoración comprensible para el rey. Crea una analogía entre el texto cultural europeo, la Biblia, y la $N C$, definiéndola así como texto cultural andino y además dotándola de una dimensión cristiana. Remitiéndose al texto cristiano-andino, el autor indígena colonial debe aparecer como buen cristiano y como fuente fiable que garantice la veracidad de lo escrito. No obstante, siendo él mismo el escritor de la obra a la que se refiere para mostrar su autoridad, tiene que probar también su integridad personal, si quiere que el rey lo escuche. Las estrategias de legitimación que utiliza las veremos en la conversación fingida.

En primer lugar, resulta llamativa la supuesta aprobación y estimación que tendría el rey hacia el consejero indígena. Esto se hace evidente en el tratamiento de Don con el que se dirige Felipe III al autor. Además, el rey empieza una de sus preguntas de la siguiente manera: "Pues dime, autor, pues que soys nieto de Topa Ynga Yupanqui, dézimo rrey que fue, y soys hijo de su segunda y de su bizorey"44. Con eso, parece que el rey reconociera el reino de los Incas y contradijera abiertamente la política de su virrey en Perú, Toledo, quien, en reacción contraria a las tesis de Las Casas, trabajó intensivamente en las últimas décadas del siglo XVI en la distribución de una versión de la historia que presentaba a los incas como usurpadores y tiranos, deslegitimando el incanato en los $\mathrm{Andes}^{45}$.

Una comparación cuantitativa de la participación en la conversación fingida muestra que lo que dice el rey constituye solo un quinto de lo dicho. Su figura se ve, además, restringida a hacer preguntas y ruegos y en ningún punto se observa el desarrollo de una discusión en la que el rey tuviera una opinión propia o divergente del autor. Esa forma narrativa se aproxima tanto a una conversación entre señor feudal europeo y vasallo como a la narración oral. Así, las preguntas del rey, por un lado, pueden representar el pedido del señor feudal por el consilium de su vasallo; por otro, pueden imitar la participación del público de una cultura oral, que quiere animar al narrador a continuar con su historia: "Pues declárame, autor, de esa declaración que decís" ${ }^{46}$. En cada caso, dado que se trata de un interlocutor fingido, Guamán Poma es el que domina la conversación, es decir, el que provoca las preguntas para seguir un hilo de narración conveniente para él. Así, por ejemplo, en estos casos:

[GP]: De que le conste a vuestra Magestad un yndio llamado don Cristóbal de León, gran seruidor de Dios y de vuestra Magestad.

\footnotetext{
${ }^{44} \mathrm{NC}, 991$.

${ }^{45}$ Gareis, Die Geschichte, 69.

${ }^{46} \mathrm{NC}, 988$.
} 
[Rey]: Dime, autor, que ¿cómo cirue a Dios y a mi corona ${ }^{47}$ ?

[GP]: Pregúnteme, vuestra Magestad, del remedio desto.

[Rey]: Pues dime, autor, ¿qué rremedio para ello ${ }^{48}$ ?

El hecho de ser digno de la estimación y confianza (fingida) del rey, lo justifica Guamán Poma con su estatus de indio ladino, el cual define Adorno como sigue: "El indígena que sabía español y vivía en la zona de contacto directo entre la temprana sociedad colonial española y la nativa"49. De esta forma contradice decisivamente el concepto negativo que circulaba en la sociedad colonial referente a los indios ladinos, según el cual era de suponer que este grupo usaba sus conocimientos interculturales exclusivamente para falsificar informaciones para su propio usufructo. Guamán Poma, no obstante, atribuye las falsificaciones a los españoles que, según él, tenían miedo de ser desenmascarados por los indios ladinos, perdiendo así su posición de poder:

Digo a vuestra Magestad, para que conste la uerdad, vuestra Magestad enbía jueses y justicias y perlados, obispos y canónigos, deán, para que le faboresca a los señores principales y pobres yndios. Dízele a vuestra Magestad que yo faboreseré, cí, cí, que haré justicia. Pero saliendo de la puerta de la mar, se muda otro hombre: antes a de faboreser a los rricos españoles ${ }^{50}$.

El rey en esta versión viene a ser la víctima de las mentiras de sus súbditos, y Guamán Poma aparece como su salvador.

Mientras que con eso el autor marca positivamente la diferencia entre él y los españoles, usa su europeización, es decir, su conversión al cristianismo y su alfabetización, para separarse de la masa de los indígenas. Los conocimientos de la lengua española y de la escritura le ofrecen una posibilidad de participar del discurso oficial, posibilidad que queda fuera del alcance de otros indígenas que carecen de conocimientos comparables. Por esta razón, así dice, le corresponde una posición privilegiada "como segunda persona del Ynga y de vuestra [Magestad]",51.

La función de representante, en la que se ve a sí mismo y a sus descendientes, continúa con la tradición familiar, dado que, según la $N C$, el padre del autor era representante del inca. Esta pretensión es comprensible, pues en el territorio

${ }^{47} N C, 990$.

${ }^{48} N C, 997$.

49 Adorno, introducción a Nueva Corónica, xviii. Para un análisis detallado de Guamán Poma como indio ladino y acompañante de visitadores españoles, véase Rolena Adorno, "La visión del visitador y el indio ladino", Cultures et sociétés Amdes et Méso-Amérique. Mélanges en hommage à Pierre Duviols, ed. Raquel Thiercelin (Aix-en-Provence, Francia: Université de Provence 1991), 1: 35-50.

${ }^{50} N C, 990$, Resaltados de la autora.

${ }^{51} N C, 985$. 
colonial era corriente que la élite provincial andina conservara sus cargos, siempre y cuando mostrara lealtad a los nuevos soberanos. La función de representante que Guamán Poma menciona hace referencia tanto al rey incaico como al español, con lo cual sugiere otra vez la legitimidad de los reyes incaicos.

Las sugerencias que, como su "vasallo", Guaman Poma presenta al rey en la fingida conversación para mejorar la situación colonial están en su mayor parte basadas en principios andinos, como en el ejemplo que sigue: "Dime, autor, ¿cómo se hará rrico los yndios? -A de sauer vuestra Magestad que an de tener hazienda de comunidad que ellos les llama sapci" ${ }^{, 52}$. Sapci, según el diccionario de Holguín (1608), es "cosa común de todos" e indica una característica antigua y central de la economía andina, en clara oposición con los derechos de propiedad vigentes en el sistema de encomienda de la sociedad colonial. La distribución de encomiendas y el derecho de sucesión habían ya causado una controversia entre los colonizadores todavía no resuelta del todo. Felipe II había prohibido la concesión de encomiendas en 1564, pero, en lo concerniente al procedimiento con las ya existentes, todavía no existía una regla definitiva. Mientras que los autores españoles de ese tiempo presentaron sus razones en favor o en contra de la perpetuidad de la encomienda, Guamán Poma propugnó por el retorno a la sapci andina.

Otras sugerencias suyas, basadas en principios andinos, conciernen, por ejemplo, a la entrega por rotación del capital humano como tributo al rey, la política de distribución, las medidas de protección para los trabajadores en las minas, etc. Solo con el retorno a estas formas, opina el autor, la extinción de la población andina podría ser evitada, asegurando calma y paz en el territorio colonial y, con eso, el reconocimiento y las ganancias de la Corona real española. Describiendo a los antiguos gobernantes y élites como administradores y políticos hábiles, que habían sido capaces de asegurar un orden armónico y justo, así como el sustento de todos sus habitantes, Guamán Poma revalúa los reinos precolombinos y los opone a la realidad colonial.

\section{Conclusión}

Volviendo al dibujo de la conversación fingida ${ }^{53}$, podemos proponer algunas conclusiones en referencia a la traducción de la memoria andina para un público europeo, en lo que atañe al traductor indígena Guamán Poma de Ayala: las informaciones que el autor posee de fuentes orales deben ser elaboradas por escrito para ser escuchadas por el destinatario. Con esto, se efectúa una transferencia a un nuevo medio útil para la memoria, usando tanto texto como dibujos, y la traducción

${ }^{52} N C, 977$.

${ }^{53} \mathrm{NC}, 975$. 
de textos culturales andinos al español. La crónica es presentada como mediadora entre el rey y el autor indígena, visto que, en primer lugar, en el contexto colonial solo lo que estaba fijado por escrito poseía fuerza probatoria y legitimidad; en segundo lugar, porque Guamán Poma sólo podía superar la distancia geográfica que lo separaba de su destinatario sirviéndose del documento escrito. Guamán Poma, como el redactor de la crónica, se presenta a sí mismo como el traductor fiable de textos culturales.

Con el fin de obtener una posición de poder en la sociedad colonial y una mejora de la situación social de los indígenas, utiliza su competencia como traductor para presentar sus ruegos conforme a las formas europeas adecuadas al rey español. Por eso, también retoma argumentos del discurso oficial español que corresponden a su intención. No obstante esto, no se legítima solamente como indígena aculturado. Más bien utiliza su estatus como indio ladino, que implica tanto su alfabetización y cristianización como también su identidad andina, para diferenciarse a sí mismo por dos lados: por uno, frente a los españoles que abusan del sistema colonial y que muestran un comportamiento poco cristiano; por otro, de los indígenas que carecen de conocimientos del español y de la escritura. Debido a su papel como mediador en la "zona del contacto", sugiere la necesidad de un reconocimiento natural por parte del rey y justifica su exigencia por una posición privilegiada en el reino de los Andes.

\section{Bibliografía}

\section{Fuentes primarias}

Poma de Ayala, Guamáelipe. Nueva Corónica y Buen Gobierno, eds. Rolena Adorno, John V. Murra y Jorge L. Urioste. Madrid: Historia 16, 1987.

Nueva Corónica y Buen Gobierno. En Det kongelige Bibliotek. Copenhage. Obtenido de la red mundial el 15 de septiembre de 2005. 11:00 horas. http://www.kb.dk/elib.mss/poma.

Die Neue Chronik und Gute Regierung, ed. Ursula Thiemer-Sachse. CDROM. Berlín: Karsten Worm Infosoftware, 2004.

Sahagún, Bernardino de. Historia general de las cosas de Nueva España, ed. Juan Carlos Temprano. Madrid: Historia 16, 1990.

\section{Fuentes secundarias}


Adorno, Rolena. "Felipe Guaman Poma de Ayala. An Andean view of the Peruian Viceroyaliy, 1565-1615". Journal de la Societé des Américanistes (París), 65 (1978): 121-143.

. "Paradigmas perdidos. Guamán Poma examina la sociedad española colonial”. Chungará (Arica, Chile), 13 (1984): 67-91.

. "Visual Mediation in the Transition from Oral to Written Expression". New Scholar (Santa Bárbara, Estados Unidos), 10, núm.1 (1986): 181-97.

Introducción a Nueva Corónica y Buen Gobierno, por Guamán Felipe Poma de Ayala. Madrid: Historia 16, 1987: XVII-XLVII.

"La visión del visitador y el indio ladino". En Cultures et sociétés Amdes et Méso-Amérique. Mélanges en hommage à Pierre Duviols, ed. Raquel Thiercelin, i, 35-50. Aix-en-Provence Cedex: Université de Provence, 1991.

Assmann, Aleida. Erinnerungsräume. München: Beck, 1999.

Assmann, Jan. "Kollektives Gedächtnis und kulturelle Identität". En Kultur und Gedächtnis, eds. Jan Assmann y Tonio Hölscher, 9-19. Frankfurt a. M.: Suhrkamp, 1988.

Das kulturelle Gedächtnis. München: Beck, 1992.

Bachmann-Medick, Doris, ed. Kultur als Text. Die anthropologische Wende in der Literaturwissenschaft. Frankfurt a. M.: Fischer, 1996.

Bhabha, Homi. The Location of Culture. Londres, Nueva York: Routledge, 1994.

Cummins, Thomas. "La representación en el siglo XVI: La imagen colonial del Inca". En Mito y simbolismo en los Andes. La figura y la palabra, ed. Henrique Urbano, Estudios y Debates Regionales Andinos, núm 84, 87136. Cusco: CBC, 1993.

"Let me see! Reading Is for Them: Colonial Andean Images and Objects" como es costumbre tener los caciques Señores". En Native Traditions in the Postconquest World, eds. Elizabeth Hill Boone y Thomas Cummins, 91-148. Washington, D.C.: Dumbarton Oaks, 1998.

Gareis, Iris. Die Geschichte der Anderen. Zur Ethnohistorie am Beispiel Perus. Berlín: Reimer, 2003. 
González, Carlos, Hugo Rosati y Francisco Sánchez. Guaman Poma. Testigo del mundo andino. Santiago de Chile: LOM, 2002.

Gargurevich Regal, Juan. "La comunicación imposible. Información y comunicación en el Perú (siglo XVI)". En Sistema de Bibliotecas Lima: Unmsm, 2002. Obtenido de la red mundial el 15 de septiembre de 2005 1:30 p.m.

http://sisbib.unmsm.edu.pe/bibvirtual/libros/Comunicacion/Comunicacion_ imposible/indice.htm.

González Holguín, Diego. Vocabulario de la Lengva General de todo el Perv llamada Lengva Qquichua o del Inca. Lima: Unmsm, 1989 [1608].

López-Baralt, Mercedes. Ícono y conquista. Guamán Poma de Ayala. Madrid: Hiperión, 1988.

Mannheim, Bruce. "Hacia una mitografía Andina". En Tradición oral andina y amazónica. Métodos de análisis e interpretación de textos, ed. Juan Carlos Goddenzi Alegre. Biblioteca de la Tradición Oral Andina, 19: 47-79. Cuzco: CBC, 1999.

Murra, John V. Introducción a Nueva Crónica y Buen Gobierno, por Guamán Felipe Poma de Ayala. Madrid: Historia 16, 1987: il-1xiii.

Ong, Walter. Orality and Literacy. The Technologizing of the Word. Londres: Methuen, 1982.

Pacheco Ibarra, Juan José. "La pintura de los incas. Un arte olvidado". Uku Pacha (Lima), 1 (2000): 36-55.

Prada Ramírez, Fernando. Der Tanz um den Buchstaben. Die semantischen Systeme des 16 Jahrhunderts in den Anden. Theorie und Forschung, núm. 294; Ethonologie, núm 1. Regensburg: Roderer, 1994.

Sievernich, Michael. "Christianorum avaritia indorum vocatio. Eine theologische Sicht der Neuen Welt im späten 16 Jahrhundert". En Der eroberte Kontinent. Historische Realität, Rechtfertigung und literarische Darstellung der Kolonisation Amerikas, ed. Karl Kohut, 103-118. Frankfurt a. M.: Vervuert, 1991.

Torero, Alfredo. Idiomas de los Andes. Lingüística e historia. Travaux de l'Institut Français d’Études Andines, núm 162. Lima: IFEA, 2002. 
Urioste, Jorge L. Introducción a Nueva Crónica y Buen Gobierno, por Guamán Felipe Poma de Ayala, Madrid: Historia 16, 1987: lxv-lxxvii.

Fecha de recepción: 29 de abril de 2005.

Fecha de aceptación: 23 de agosto de 2005. 